\title{
Effect of processing parameters on morphology and thermal properties of electrospun polycarbonate nanofibers
}

\author{
S.R. Dhakate*, B. Singla, M. Uppal, R.B. Mathur
}

Carbon Technology Unit, Engineering Materials Division, National Physical Laboratory, CSIR, Dr. K. S. Krishnan Marg, New Delhi 110012, India

*Corresponding author. Tel: (+91) 11 45608257; Fax: (+91) 11 45609310; E-mail: dhakate@ mail.nplindia.ernet.in

Received: 4 Aug 2010, Revised: 21 Sept 2010 and Accepted: 27 Sept 2010

ABSTRACT

In the present contribution, it has been reported about the effect of solvent, solvent concentration, flow rate and applied voltage on the fabrication of electrospun polycarbonate (PC) nanofibers. The morphology of fibers was studied by optical and scanning electron microscope. It is observed that morphology of fibers depends upon the concentration of PC or viscosity of the solution, vapor pressure and diffusion coefficient of solvent. In fact, when viscosity of the solution is very low, beads or droplets are formed instead of fibers. The same problem arises when the viscosity of the solution is too high due to high surface tension. In this case, jet formation will not be observed and the solution will coagulate at the tip of needle. Tetrahydrofuran (THF) easily diffuses with polymer, at higher concentration of PC and at higher flow rate of solution; fibers of micron size are formed because of high vapor pressure of THF. On the other hand, in case of mixed solvents (DMF and THF), by controlling processing parameters one can get fiber diameter up to $200 \mathrm{~nm}$. The study of Differential Scanning Calorimetry (DSC) indicates that less amount of heat energy is absorbed during endothermic reaction and there is a slight increase in glass transition temperature of nanofibers. Thermogravimetric analysis (TGA) shows an increase in thermal stability of PC nanofibers by $40^{\circ} \mathrm{C}$ as compared to PC granules. This is due to the alignment of PC polymeric chains during stretching and whipping that occurs while electro spinning process. Copyright $\odot 2010$ VBRI press.

Keywords: Electrospinning; nanofibers; morphology; thermal properties.

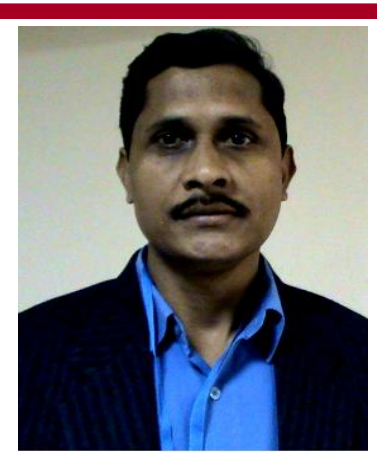

Sanjay R. Dhakate is a scientist working at the National Physical Laboratory, New Delhi, India since 1992. His research interests mainly on carbon materials such as carbon fibers, carbon-carbon composites, carbon nanotubes, graphene synthesis via exfoliation of graphite, nanoribbons by unzipping CNTs, continuous carbon nanofibers by electrospinning, alignment of carbon nanotubes by electrospinning. Development of PEM fuel cell components i.e., advanced composite bipolar plate and porous conducting carbon papers. He is a receipt of JSPS and JICA fellowship.

\section{Introduction}

The ability to shape materials of different length scales including the nanoscale is important for many applications when high surface to volume ratio materials are required. Recently, polymeric materials have received high attention to achieve morphology and size from micron to nanoscale.
Therefore, nano-material is a fascinating area and is a focus for a good deal of research activity among the researcher worldwide. The word nano usually applied to materials having dimensions $<100 \mathrm{~nm}$. However, in case of nanofibers, limit can be from 0.5 to $1 \mu \mathrm{m}[\mathbf{1 , 2}]$. There are number of synthesis and fabrication techniques demonstrated to generate polymer materials of different morphologies. Among these methods, electrospinning is a simple and versatile process to fabricate unidirectional (UD) nanoscale materials such as nanowires, nanofibers and nanotubes [3-10]. The traditional melt spinning process, spun the fibers of diameter between 5 to $200 \mu \mathrm{m}$, whereas electrospun fibers can have diameters in the nanometer range [7]. These electrospun nanofibers have potential applications in filters, tissue engineering scaffolds, wound dressing, protective clothing, reinforced nanocomposites and many others [11-16].

In electrospinning process, high electric field is applied to viscous polymer solution held in syringe, inducing a charge density on the liquid surface [17-23]. Mutual charge 
repulsion brings about a force which is directly opposite to the surface tension. When the electric field is sufficiently high, surface of the solution in the proximity of tip of the syringe is elongated and forms a cone named Taylor cone $[18,19]$. A critical value of electric field exists for which the repulsive electrical force overcomes the surface tension. As the critical value is reached, charged jet of the solution is ejected from the tip of the Tailor cone. As the jet accelerates in presence of electric field, radial charge repulsion results in to the splitting of the primary jet into multiple filaments, is a process known as splaying [24]. The final fiber size is primarily determined by number of subsidiary jets formed. A number of studies of electrospinning of various polymers have been explored in the last one decade. But only few studied reported in literature on the formation of PC nanofibers by electrospinning technique. PC is a lightweight, high performance plastic that possesses unique properties, i.e., toughness, dimensional stability, optical clarity, high heat resistance and excellent electrical resistance. Polycarbonate is used in a wide variety of application such as bullet proof transparent windows, compact disc, and digital video disc, electronic equipment, sport safety equipment and medical devices etc. In all these applications polycarbonate is used in bulk form which is molded in a particular shape and size. In present work authors have tried to prepare PC nanofibers by controlling intrinsic and process parameters and their effect on the morphology and thermal properties of nanofibers are studied.

\section{Experimental}

PC granules were procured from industrial source $(M \mathrm{w}$ 60,000). THF was procured from Qualigens fine chemical, N, N dimethylformamide (DMF) purchase from Fisher Scientific and Chloroform from Merck, India. The solutions of PC with different solvents were prepared by mixing them through multi-frequency ultrasonic bath (procured from Life Care Equipment Pvt. Ltd., Mumbai) for one hr at temperature $50^{\circ} \mathrm{C}$. The different solvents were used with PC in different ratios listed in Table $\mathbf{1}$ and properties of the solution given in Table 2 . Later on solution was mixed by magnetic stirrer for fifteen to twenty hrs to get uniformly mixed solution. The mixing of solvent and PC is dependent upon the diffusion coefficient of the solvent and polymer.

Polycarbonate fibers were electrospun by Electrospinning apparatus (ESPIN-NANO) procured from Physics Instruments Co. Chennai. Fig. 1 shows the schematic diagram of cylindrical rotating electrospinning assembly. It consists of a syringe pump, DC high voltage source and rotating cylindrical collector etc. The spinning solution was kept in a vertical syringe with a stainless steel needle having an orifice of $0.55 \mathrm{~mm}$. The needle was electrically connected to a positive high voltage. The rotating cylindrical collector of diameter $30 \mathrm{~mm}$ was placed below the syringe connected to a positive high voltage. Electrospinning was carried out at room temperature in the insulated box.

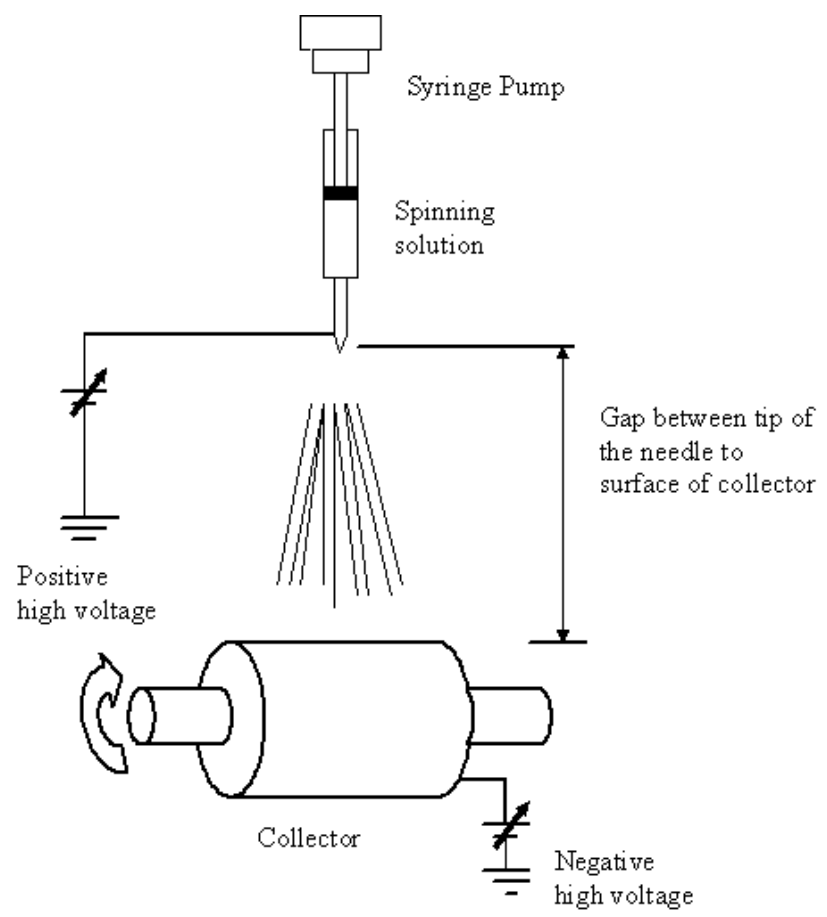

Fig. 1. Schematic representation of electrospinning assembly consisting of syringe pump, DC high voltage source and rotating cylindrical collector.

Table 1. Processing parameters of polycarbonate nanofibers.

\begin{tabular}{|c|c|c|c|c|c|c|}
\hline Sample code & $\begin{array}{l}\mathrm{PC} \\
\text { conc. }\end{array}$ & $\begin{array}{l}\text { Ratio of } \\
\text { solvent }\end{array}$ & $\begin{array}{l}\text { Applied } \\
\text { voltage }(\mathrm{kV})\end{array}$ & $\begin{array}{l}\text { Flow rate } \\
\mathrm{mL} / \mathrm{h}\end{array}$ & $\begin{array}{l}\text { Collector } \\
\text { speed }\end{array}$ & $\begin{array}{l}\text { Tip to } \\
\text { Collector } \\
\text { distance } \\
(\mathbf{c m})\end{array}$ \\
\hline 10PC-10T-10K & 10 & $\begin{array}{l}\text { THF:DMF } \\
\text { 100:00 }\end{array}$ & 10 & 0.5 & 2000 & 15 \\
\hline 10PC-5T-10K & 10 & $50: 50$ & 10 & 0.2 & 2000 & 15 \\
\hline 10PC-6T-10K & 20 & $60: 40$ & 10 & 2 & 2000 & 10 \\
\hline 15PC-5T-15K & 15 & $50: 50$ & 15 & 3 & 2000 & 10 \\
\hline 22PC:10D:15 & 22 & $00: 100$ & 15 & 0.5 & 2200 & 15 \\
\hline 20PC-5T-15K & 20 & $50: 50$ & 15 & 1 & 2000 & 10 \\
\hline 20PC-6T-10K & 20 & $60: 40$ & 10 & 2 & 3000 & 10 \\
\hline 20PC-5T-10K & 20 & $50: 50$ & 10 & 1 & 2000 & 10 \\
\hline 20PC-5T-15K & 20 & $50: 50$ & 15 & 2 & 2000 & 10 \\
\hline 22PC-5T-15K & 22 & $50: 50$ & 15 & 2 & 2000 & 10 \\
\hline 22PC-6T-10K & 22 & $60: 40$ & 15 & 2 & 2500 & 15 \\
\hline 22PC-5T-10K & 22 & $50: 50$ & 10 & 3 & 2000 & 15 \\
\hline 22PC-5T-10K & 22 & $50: 50$ & 14 & 0.5 & 2000 & 10 \\
\hline 22PC-5T-10K & 22 & $50: 50$ & 10 & 0.5 & 2000 & 10 \\
\hline 23PC-6T-10K & 23 & $60: 40$ & 10 & 0.5 & 2000 & 10 \\
\hline 24PC-6T-10K & 24 & $60: 40$ & 10 & 0.5 & 2000 & 10 \\
\hline 20PC-6T-10K & 20 & $60: 40$ & 10 & 3 & 2000 & 10 \\
\hline 20PC-6T-15K & 20 & $60: 40$ & 15 & 3 & 2000 & 15 \\
\hline 20PC-6T-15K & 20 & $60: 40$ & 15 & 0.5 & 2000 & 15 \\
\hline 21PC-6T-15K & 21 & $50: 50$ & 15 & 0.5 & 2100 & 15 \\
\hline 21PC-6T-15K & 21 & $50: 50$ & 15 & 3 & 2200 & 15 \\
\hline 21PC-6T-15K & 21 & $50: 50$ & 15 & 0.2 & 2300 & 15 \\
\hline 30PC:10T:15 & 30 & 100:00 & 15 & 3 & 2300 & 10 \\
\hline 44PC:10T:15 & 44 & 100:00 & 15 & 3 & 2300 & 10 \\
\hline \multirow[t]{2}{*}{ 23PC-6CL-10K } & & $\mathrm{CHCl}_{3}: \mathrm{DMF}$ & & & & \\
\hline & 23 & $65: 35$ & 10 & 0.5 & 2000 & 10 \\
\hline 23PC-6CL-10K & 23 & $65: 35$ & 10 & 1 & 2500 & 10 \\
\hline 23PC-6CL-10K & 23 & $66: 35$ & 10 & 1 & 2500 & 15 \\
\hline 23PC-6CL-10K & 23 & $65: 35$ & 15 & 1 & 2000 & 15 \\
\hline 23PC-6CL-10K & 23 & $65: 35$ & 10 & 0.5 & 2500 & 15 \\
\hline 23PC-10CL-10K & 23 & 100:00 & 15 & 0.5 & 2300 & 15 \\
\hline
\end{tabular}


Table 2. Properties of solvent.

\begin{tabular}{cccccc}
\hline Solvent & $\begin{array}{c}\mathrm{Tb} \\
\left({ }^{\circ} \mathrm{C}\right)\end{array}$ & $\begin{array}{c}\mathrm{Tm} \\
\left({ }^{\circ} \mathrm{C}\right)\end{array}$ & $\begin{array}{c}\text { Density } \\
(\mathrm{g} / \mathrm{cc})\end{array}$ & $\begin{array}{c}\text { Viscosity at } 20^{\circ} \mathrm{C} \\
(\mathrm{mPa} . \mathrm{s})\end{array}$ & $\begin{array}{c}\text { Vapor pressure } \\
(\mathrm{kPa})\end{array}$ \\
\hline $\mathrm{THF}$ & 66 & -108 & 0.8892 & 0.468 & 21.0 \\
$\mathrm{DMF}$ & 153 & -61 & 0.944 & 0.92 & 2.7 \\
$\mathrm{CHCl}_{3}$ & 62 & -63.5 & 1.48 & 0.568 & 26.2 \\
\hline
\end{tabular}

The positive high voltage of $10-20 \mathrm{kV}$ was applied to the needle, reported in Table 1. The rotational speed of the rotating cylindrical collector during electrospining varies from between 1000-3000 rpm and solution flow rate between 0.10 to $3.0 \mathrm{~mL} / \mathrm{h}$ was maintained using computer control programmer. Morphology of electrospun fiber was studied by polarized light microscope (Zeiss, model MC80 DX) and scanning electron microscope (SEM, Zeiss-EVO, MA-10, variable UK). Differential Scanning Calorimetry (DSC, Metter Toledo system) was used to characterize PC and PC based nanofibers to check if there was any change occurs in the properties of electrospun fibers. The DSC was performed in nitrogen atmosphere at heating rate $5^{\circ} \mathrm{C} / \mathrm{min}$ up to $500^{\circ} \mathrm{C}$. Thermal stability of $\mathrm{PC}$ and $\mathrm{PC}$ nanofibers in $\mathrm{N}_{2}$ from room temperature to $1000^{\circ} \mathrm{C}$ was measured by thermo gravimetric analysis (TGA/SDTA $851^{\circ}$, Metter Toledo system).

\section{Results and discussion}

The surface morphology of electrospun PC fibers is observed by optical and scanning electron microscope. It is observed that at lower concentration of PC (10 wt.\%) with individual solvent THF and DMF (Fig. 2a, optical micrograph), droplets are collected on the rotating cylindrical collector rather than fibers even up to $20 \mathrm{wt} \%$ of PC. These droplets formation can be termed as electrospray [25]. The solution prepared with the solvent ratio of THF: DMF: 50:50, even at 15\% concentration of PC, fibers are not formed (Fig. 2b, optical micrograph). With increasing the concentration of PC up to $20 \mathrm{wt} \%$ with keeping all variable constant, nanofiber with spindle type beads are collected on collector (Fig. 2c, SEM). It is observed that the jet of polymer solution from tip of syringe capillary begins to break-up in to droplet at concentration below $20 \%$ of PC. At lower concentration, the charged polymer solution jet initiating from the Taylor cone breaksup in to droplets in mill seconds rather than several second. Therefore, because of abruptness of the process, solution droplets are formed instead of fibers; polymer has aggregate and solidifies due to the higher vapor pressure of the solvent. On the other hand at $22 \%$ of PC with DMF, viscosity of the solution increases even though bigger circular droplets are observed due to the very low vapor pressure of the DMF based PC solution.

However, chloroform as a solvent with $23 \mathrm{wt} \%$ of PC, fibers are formed with irregular surface because the vapor pressure of chloroform is comparatively high and viscosity also increases with increasing PC content to $23 \%$ (Fig. 2d, optical micrograph). This type of morphology is due to the incomplete diffusion of solvent in polymer and as a result there is not uniform evaporation of solvent. On addition of $30 \%$ of DMF in chloroform with $23 \%$ of PC, fiber forms with smaller beads i.e., rough surface, this might be due to lower diffusion of solvent in polymer (Fig. 2e). However, addition of 70\% DMF (Vp $2.7 \mathrm{kPa})$ in chloroform (Vp 26.2 $\mathrm{kPa})$ reduces the vapor pressure of solution as well as diffusion of DMF with polymer is comparatively good. Also due to higher content of DMF, viscosity of the solution increases and as a result electrospun fibers with smooth fibers surface, even though some amount of circular beads or droplet are observed (Fig. 2f).

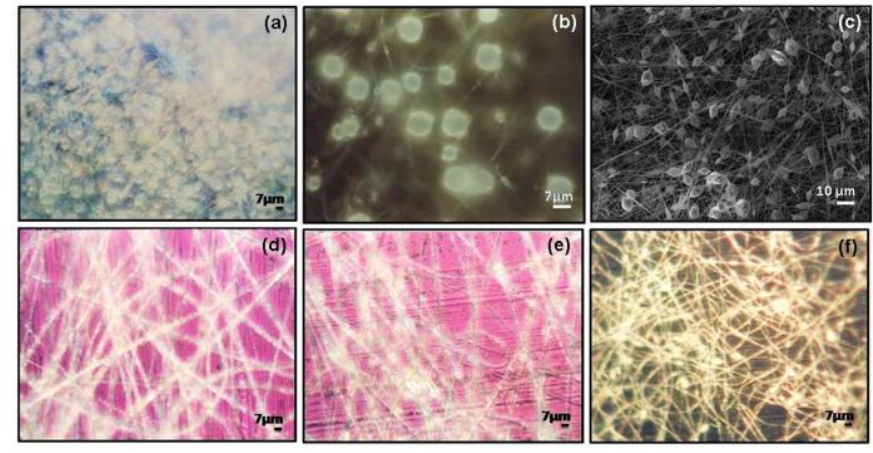

Fig. 2. Optical micrograph of electrospun $\mathrm{PC}$ at (a) $10 \mathrm{wt} \%$ with $\mathrm{THF}$ solvent (b) $15 \mathrm{wt} \%$ with THF and DMF solvent ratio 50:50 (c) SEM micrograph nanofibers with $20 \mathrm{wt} . \%$ of PC, (d) $23 \mathrm{wt} \%$ PC with $100 \%$ chloroform (e) $23 \mathrm{wt} \% \mathrm{PC}$ with $70 \%$ chloroform (f) $23 \mathrm{wt} \% \mathrm{PC}$ with $30 \%$ chloroform content.
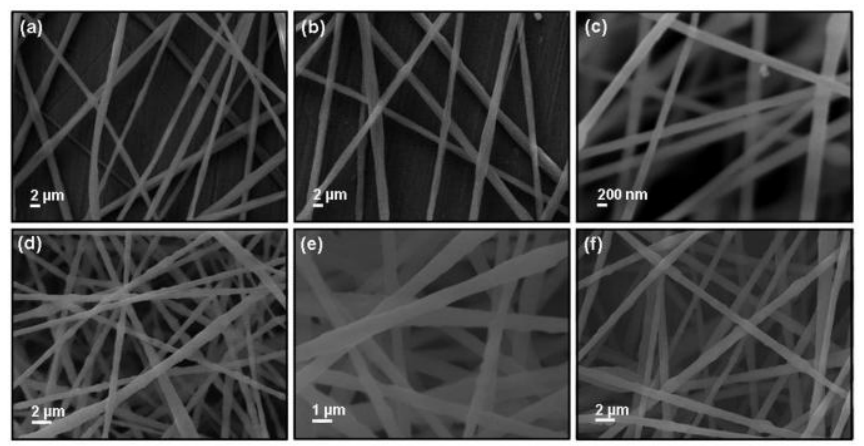

Fig. 3. SEM micrographs of PC electrospun nanofibers from solution contain $65 \% \mathrm{CHCl}_{3}$ and $35 \%$ DMF with $23 \%$ PC contains( a) flow rate $1 \%$ (b) 0.5\%, PC content 20 wt \% , THF: DMF:: 50:50 (d) PC content 20 wt \%, THF:DMF:: 60:40 (e) PC content 22 wt\%, THF:DMF-50:50 (f) PC content $22 \mathrm{wt} \%$, THF: DMF ratio 60:40.

Fig. 3 shows the SEM micrographs of PC nanofibers electrospun from solution containing $65 \%$ Chloroform and $35 \%$ DMF with 23 wt\% of PC. Fig. 3a and b, fibers are somewhat ribbon shaped with rough surface (fibers are not with circular cross section). In both cases only difference is in the flow rate solution, at flow rate of $1 \mathrm{~mL} / \mathrm{h}$, variation in fiber diameter is less than fibers electrospun at flow rate 0.5 $\mathrm{mL} / \mathrm{h}$ (Fig. 3b). The addition of DMF increases the viscosity of solution. The non uniformity in fiber surface morphology basically depends upon the evaporation rate of solvent as well as viscosity. During solvent evaporation, solution becomes thermodynamically unstable and phase separation occurs in to a polymer rich and polymer lean phase. This depends upon the diffusion coefficient of solvent and polymer. In both the cases fibers diameter is in between 1- $2 \mu \mathrm{m}$. In case of higher flow rate of the solution, solvent evaporation rate is uniform and role of phase separation is less. 
At $20 \%$ of PC with THF:DMF ratio 50:50 at flow rate $1 \mathrm{~mL} / \mathrm{h}$ and applied voltage $10 \mathrm{kV}$, electrospun fibers have diameter up to $250 \mathrm{~nm}$ (Table 3). However, with increasing applied voltage $(15 \mathrm{kV})$ with keeping other parameters constant, electrospun fiber forms without beads of diameter between 100-300 $\mathrm{nm}$ are collected on the collector (Fig. 3c).

Table 3. Processing parameters of electro spun fiber drawn from THF:DMF solvent.

\begin{tabular}{llllll}
\hline $\begin{array}{c}\text { PC } \\
\text { content }\end{array}$ & THF:DMF & $\begin{array}{c}\text { Voltage } \\
(\mathbf{k V})\end{array}$ & $\begin{array}{c}\text { Flow rate } \\
(\mathbf{m L} / \mathbf{h})\end{array}$ & $\begin{array}{c}\text { Collector } \\
\text { speed (RPM) }\end{array}$ & Fiber diameter \\
\hline 20 & $50: 50$ & 10 & 1.0 & 200 & $100-250 \mathrm{~nm}$ \\
20 & $50: 50$ & 15 & 1.0 & 2000 & $100-300 \mathrm{~nm}$ \\
20 & $60: 40$ & 10 & 2.0 & 3000 & $700-1100 \mathrm{~nm}$ \\
22 & $50: 50$ & 15 & 2.0 & 2000 & $500-900 \mathrm{~nm}$ \\
22 & $60: 40$ & 10 & 0.5 & 2000 & $600-800 \mathrm{~nm}$ \\
30 & $60: 40$ & 15 & 3.0 & 2000 & $4-7 \mu \mathrm{m}$ \\
44 & $100: 00$ & 15 & 3.0 & 2000 & $10 \mu \mathrm{m}$ \\
\hline
\end{tabular}

On increasing THF content to $60 \%$ and solution flow rate to $2 \mathrm{~mL} / \mathrm{h}$, vapor pressure of the solvent increases and as a result increases in fiber diameter to 700-1100 nm but fibers with some beads (Fig. 3d). With increasing PC content up to $22 \%$ at solvent ratio 50:50, fiber diameter varies from $500-900 \mathrm{~nm}$ but the surface of the fiber is rough (Fig. 3e). With increasing $\mathrm{PC}$ content to $23 \%$, THF content $60 \%$ and flow rate $0.5 \%$, fiber diameter slightly decreases to $600-800 \mathrm{~nm}$ but fiber with some spindle type beads are formed (Fig. 3f). This could be due to the lower flow rate of the solution. In Fig. 4 (a and b), illustrated the optical micrographs of nano fiber with ratio of solvent, THF: DMF: 60:40 at PC content 22 and $23 \mathrm{wt} \%$. In both the cases, fibers with some spindle type beads are noticed. With increasing the PC content to $30 \%$ in single solvent system $\mathrm{THF}$ and flow rate $3 \mathrm{ml} / \mathrm{hr}$, twisted ribbon shape fibers of diameter 4-7 $\mu \mathrm{m}$ are collected. Further with increasing the $\mathrm{PC}$ content to $44 \mathrm{wt} \%$ and solution flow rate $3 \mathrm{~mL} / \mathrm{h}$, the ribbon shaped fibers without any beads are collected on the collector with $100 \%$ THF. It is found that at higher $\mathrm{PC}$ content, electrospun fiber diameter increases upto10 $\mu \mathrm{m}$ (Fig. 4c).
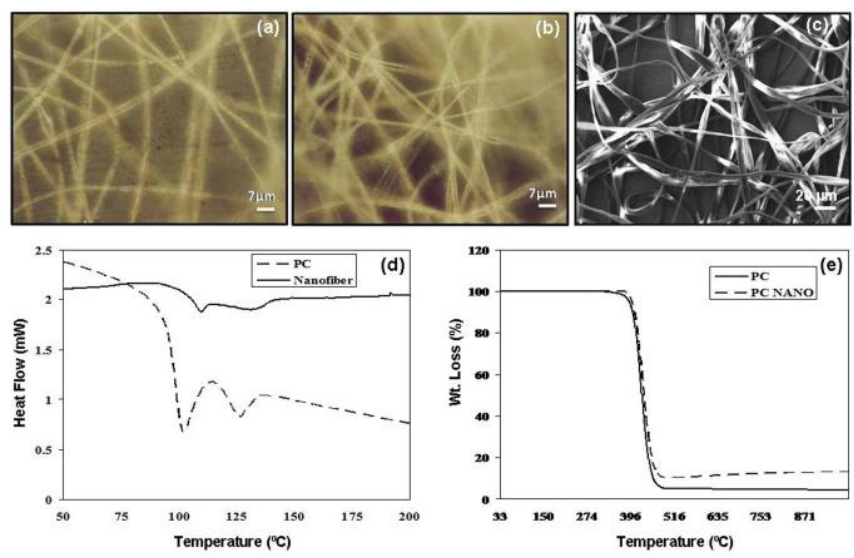

Fig. 4. PC nano fibers electrospun with solvent ratio of THF:DMF:: 60:40 at PC content (a) 22\%, (b) 23\%, (c) 44\% and (d) DSC curve, (e) TGA curve of $\mathrm{PC}$ and electrospun $\mathrm{PC}$ nanofibers.
Fig. 4d shows the DSC curve of PC granule and its electrospun nanofibers. It is observed that in case of PC granules endothermic peak occur at glass transition temperature $(\mathrm{Tg}) 101.64^{\circ} \mathrm{C}$ while in PC nanofibers it occurs at $109.6^{\circ} \mathrm{C}$. However, Macossary et al. [26], reported the $\mathrm{Tg}$ of PMMA nanofibers is lower as compared to $\mathrm{Tg}$ of PMMA powder, this is due to the water absorption from the surrounding as the nanofibers travel from the needle to the target, water absorbed would plasticize the nanofibers and decreases the Tg. But once the water is removed from the nanofibers, the glass transition temperature coincided with powder PMMA. But our studies are not in agreement with the Macossary observations because our processing carried out in the closed insulating box.

On electrospinning of PC solution, semi crystalline polymer changes to amorphous, in this atoms are linked together and form long polymeric chain where the intermolecular force is supposed to be appreciable but not too strong. Increase in $\mathrm{Tg}$ related to orientation of polymeric chain in particular direction due to the stretching and whipping that occurs while during electro spinning process. This can give the high impact strength to the ultimate material. The increase in $\mathrm{Tg}$ of PC nanofibers attributes to the change in behavior i.e. strong and tough with improved impact resistance of nanofibers. This has resulted in to the decrease in the value of enthalpy. In case of PC granules, heat energy absorb is higher $(3.55 \mathrm{~J} / \mathrm{g})$ as compared to PC nanofibers $(2.71 \mathrm{~J} / \mathrm{g})$. However, 2nd endothermic peak is due to the decomposition of polymer (Fig. 4f). In case of PC granules, endothermic peak observed at $420^{\circ} \mathrm{C}$ and amount of energy absorbed in the form of enthalpy is found to be $582.7 \mathrm{~J} / \mathrm{g}$. Whereas, in case of PC nanofibers the endothermic peak temperature is almost same with different enthalpy value. This is due to the higher surface area of nanofibers. The amount of energy absorbed is higher and maximum enthalpy of $683 \mathrm{~J} / \mathrm{g}$ in case of nanofibers is derived from $22 \mathrm{wt} \% \mathrm{PC}$ in the solution.

TGA curve of PC granules and electro spun PC nanofibers is illustrated in Fig. 4f. The decomposition take place in both cases is in single step. The weight loss in PC granules and PC nanofibers is initiated above 340 and 380 ${ }^{\circ} \mathrm{C}$, respectively. So there is an increase in thermal stability of nanofibers by $40^{\circ} \mathrm{C}$. The decomposition is started above $340^{\circ} \mathrm{C}$ and maximum weight loss is observed up to $430^{\circ} \mathrm{C}$ whereas total weight loss in PC granules is $95 \%$. However, in case of nanofibers decomposition started above $380^{\circ} \mathrm{C}$ and completed at $470^{\circ} \mathrm{C}$. It shows that within the span of $90^{\circ} \mathrm{C}$ maximum weight loss occurs. Total weight loss is $86.8 \%$ in nanofibers. This clearly brings out the fact that due to the alignment of polymeric chain during electro spinning process, thermal stability of nanofibers increases. These observations are in agreement with the studies of Kim et al. [27] and Zong et al. [28]. In their study, they have electrospun poly (ethylene terephthalate) and poly (Llactic acid) into nanofibers. The nanofibers thermal stability is higher as compared to as such polymer which is due to the ordered structure of electro spun fibers. 


\section{Conclusion}

In this contribution, morphology and thermal properties of electrospun nanofibers are investigated as a function of several electrospinning parameters. It is observed that the morphology of fibers depends upon the concentration of PC or viscosity of the solution, vapor pressure and diffusion coefficient of solvent. In fact, when viscosity of the solution is too low, beads or droplets are formed instead of fiber. The same problem arises when the viscosity of the solution is too high because of high surface tension. In this case, jet will not be formed and the solution coagulates at the tip of needle. The THF is easily diffused with the polymer but due to the high vapor pressure of solvent, smooth surface of nanofibers is not formed. However, at high concentration $\mathrm{PC}$ and flow rate of the solution, fibers of micron size are formed because of high vapor pressure of THF. It is observed that the surface morphology and diameter of fiber very much depends upon the flow rate of the solution. On the other hand, in case of mixed solvents (DMF and THF) by controlling processing parameter one can get fiber diameter up to $200 \mathrm{~nm}$. The DSC studies reveal that heat energy absorbed by nanofibers is less during endothermic reaction and there is slight increase in $\mathrm{Tg}$ of nanofibers. TGA study indicates the increase in thermal stability of PC nanofibers by $40^{\circ} \mathrm{C}$ when compared to $\mathrm{PC}$ granules. This is due to the PC polymeric chains aligned during stretching and whipping that occurs in electro spinning process. These studies help in the production of PC nanofibers with appropriate ratio of polymer and solvent for different applications.

\footnotetext{
Acknowledgements

The authors are highly grateful to Prof. R.C. Budhani, Director, NPL (CSIR), for his kind permission to publish the results. Also thanks to Mr. R. K. Seth for thermal measurements and Mr. Jai Tawale for providing SEM characterization facilities.
}

\section{References}

1. Hagewood, J.F.; Wilkie, A. Nonwoven world 2003, 12, 69.

2. Hagewood, J.F. International Fiber Journal 2004, 19, 48

3. Reneker, D.H.; Yarin, A.L.; Fong, H.; Koombhongses, S. J. Applied Physics 2000, 87, 4531

4. Doshi, J.; Reneker, D.H. J. Applied and Polymer Science 1995, 35 , 150.

5. Ramakrishna, S.; Fujihara, K.; Teo, W.E.; Yong, T.; Ma, Z.; Ramaseshan, R. Materials Today 2006, 9, 40.

6. Huang, Z.M.; Zhang, Y.Z.; Kotaki, M.; Ramakrishna, S. Composites Science and Technology 2003, 63, 2223.

7. Reneker, D.H.; Chun, L. Nanotechnology 1996, 7, 216.

8. Theron, A.; Zussman, E.; Yarin, A.L. Nanotechnology 2001, 12, 384.

9. Yarin, A.L.; Koombhongses, S.; Reneker, D.H.; J. Appl. Phys. 2001, $89,3018$.

10. Bognitzki, M.; Czando, W.; Frese, T.; Schaper, A.; Hellwig, M.; Steinhart, M.; Greiner, A.; Wendorff, J.H. Adv. Mater. 2004, 16, 1151.

11. Ramakrishna, S.; Fujihara, K.; Teo, W.E. Materials Today 2006, 9 , 40.

12. Huang, Z.M.; Zhang, Y.Z.; Kotaki, M.; Ramkrishna, S. Composite Sci Tech. 2003, 63, 2223.

13. Yoshimoto, H.; Shin, Y.M.; Terai, H.; Vacanti, P. Biomaterials 2003 , 24, 2077.

14. Macossay, J.; Leal, J.L.; Kuang, A.; Jones, R.E. Polym. Adv. Technol. 2006, 17, 391

15. Ding, B.; Kim, J.; Miyazaki, Y.; Shiratori, S. Sensors and Actuator B 2004, 101, 373 .

16. Kenawy, E.R.; Bowlin, G.L.; Mansfield, K.; Layman, J.; Simpson, D.G.; Sanders, E.H.; $\quad$ Wnek, G.E. Control Release 2002, 81, 57.
17. Dharmaraj, N.; Park, H.C.; Lee, B.M.; Viswanathamurthi, P.; Kim, H.Y.; Lee, D.R. Inorg. Chem. Commun 2004, 7, 431.

18. Shin, Y.M.; Hohman, M.M.; Brenner, M.P.; Rutledge, G. C. Appl. Phys. Lett. 2001, 78, 1149.

19. Hohman, M.M.; Shin, M.; Rutledge, G.; Brenner, M.P. Phys. Fluids 2001, 13, 2221.

20. Fridrikh, S.V.; Yu, J.H.; Brenner, M.P. Rutledge, G.C. Phys. Rev. Lett. 2003, 90, 144502.

21. Theron, S.A.; Zussman, E.; Yarin, A.L. Polymer 2004, 45, 2017.

22. Tan, S.H.; Inai, R.; Kotaki, M.; Ramakrishna, S. Process. Polymer $\mathbf{2 0 0 5}, 46,6128$.

23. Thompson, C.J.; Chase, G.G.; Yarin, A.L.; Reneker, D.H. Polymer 2007, 48, 6913.

24. Doshi, J.; Renekar, D.H. J. Eelctrostatics 1995, 35, 151.

25. Wang, H.; Liu, Q.; Yang, Q.; Zhang, C.; Li, Y. 2010, 45, 1032.

26. Macossary, J.; Marruffo, A.; Rincon, R.; Eubanks, T.; Kuang, A. Polym. Adv. Technol. 2007, 18, 180.

27. Kim, J.S.; Lee, D.S. Polym. J. 2000, 32, 616

28. Zong, X.; Kim, K.; Fang, D.; Ran, S.; Hsiao, B.; Chu, B. Polymer 2002, 43, 4403 